\title{
Educar para a diversidade e cidadania: compreensões, desafios e perspectivas
}

EDUCATING FOR DIVERSITY AND CITIZENSHIP: UNDERSTANDINGS,
CHALLENGES, AND PERSPECTIVES ANTONIO ANDRESON OLIVEIRA SILVA (iD) 1

RAIMUNDO NONATO FERREIRA DO NASCIMENTO (iD2

\section{Resumo}

O reconhecimento e a valorização das diversidades no espaço educativo tem sido uma constante nos debates e reflexões no campo educacional, ao mesmo tempo em que tem se constituído um discurso que uma das funções da escola é educar para a cidadania. Assim, o presente artigo tem por objetivo refletir sobre como estes conceitos - diversidade e cidadania - são compreendidos e operacionalizados no contexto educativo. Para tanto, tomamos como lócus de investigação uma escola da rede pública estadual do município de Teresina-PI, onde, por meio de entrevistas, conversas informais e sobretudo, da observação procuramos perceber se e como essa escola vem compreendendo e promovendo o reconhecimento da diversidade e a formação para a cidadania. Nesse processo analítico, dialogamos com autores da área de educação, história e antropologia que nos ajudam a melhor entender as ações e práticas discursivas no interior da escola.

Palavras-chave: Cidadania; Diversidade; Educação; Escola e Reconhecimento.

${ }^{1}$ Universidade Federal do Piauí. E-mail: antonyoandreson@gmail.com

2 Universidade Federal de Pernambuco. E-mail: nonatorr.33@gmail.com 


\section{Abstract}

The recognition and valorization of diversities in the educational space has been a constant in the debates and reflections in the educational field, at the same time as a discourse has been constituted that one of the roles of the school is to educate for citizenship. Thus, this article aims to reflect on how these concepts - diversity and citizenship - are understood and operationalized in the educational context. To do so, we took as locus of investigation a public school in the city of Teresina-Pl, where, through interviews, informal conversations and, above all, observation, we tried to understand if and how this school has been understanding and promoting the recognition of diversity and education for citizenship. In this analytical process, we dialogued with authors from the fields of education, history, and anthropology that help us to better understand the actions and discursive practices inside the school.

Keywords: Citizenship; Diversity; Education, School and Recognition.

\section{Resumen}

El reconocimiento y la valoración de las diversidades en el espacio educativo han sido una constante en los debates y reflexiones en el ámbito educativo, en el mismo tiempo que se ha constituido el discurso de que una de las funciones de la escuela es educar para la ciudadanía. Así, este artículo intenta reflexionar sobre cómo se entienden y operacionalizan estos conceptos -diversidad y ciudadanía- en el contexto educativo. Para ello, tomamos como locus de investigación una escuela pública del municipio de Teresina-PI, donde, a través de entrevistas, conversaciones informales $y$, sobre todo, de la observación, tratamos de entender si y como en esta escuela han estado entendiendo y promoviendo el reconocimiento de la diversidad y la educación para la ciudadanía, y cómo lo han hecho. En este proceso analítico, dialogamos con autores del campo de la educación, historia y antropología que nos ayudan a comprender mejor las acciones y prácticas discursivas dentro de la escuela.

Palabras clave: Ciudadanía; Diversidad; Educación, Escuela y Reconocimiento.

\section{Introdução}

A educação segundo Brandão (2008), está em todas as sociedades e se faz presente em casa, na rua, na igreja ou na escola. Por esta razão, ninguém escapa à educação. Nesse sentido, não há uma forma ou modelo único de educação e a escola não é o único espaço onde ela acontece. Cada sociedade, de uma forma ou de outra, 
educa seu povo e por meio da educação molda-os a depender do tipo de sociedade que se deseja formar.

Ao partir dessa perspectiva apresentada por Brandão, compreendemos que o desenvolvimento das sociedades está vinculado ao desenvolvimento da educação. E aqui, compreendemos a educação desde uma perspectiva apontada por Gusmão (1997), que a entende não apenas como um processo formal de ensino, mas como uma dimensão holística que vai do caos a ordem, para outra ordem, que se desconstrói com bases em pressupostos construtivos, posto em movimento pela vivência e pela experiência, pois se trata de um processo de utilização da cultura gerando um fazer reflexivo e crítico.

Nesse sentido, a prática da educação é muito anterior ao pensamento pedagógico, sendo este último, resultado das reflexões sobre a prática e da necessidade de sistematizá-la e organizá-la em função de determinados objetivos. É, a partir dessa necessidade de sistematização e reflexão do fazer educativo que surge a escola. Esta, enquanto instituição social tem se constituído de uma importância fundamental no processo de construção e divulgação do saber. Desde sua criação até a atualidade, muitos debates são provocados e contextualizados nesse campo e ocorre devido ao fato de à instituição escolar ser atribuída uma grande responsabilidade: propiciar o acesso ao saber sistematizado, ou seja, a ciência, bem como o próprio acesso aos rudimentos do saber (Saviani, 2013), e na atualidade ainda lhe é delegada a responsabilidade de formar cidadãos críticos, conscientes de seus direitos e deveres, ou seja, educar para a cidadania.

Ao tomar como pressuposto que uma das funções da escola é "educar para a cidadania", podemos nos questionar; o que é, e como educar para a cidadania? Como a escola em sua práxis educativa, vem promovendo essa formação e quais os pressupostos teóricos que balizam essa ação?

É, portanto, sobre os questionamentos acima que nos dedicaremos nos limites desse artigo. O intuito não é respondê-los, mas iniciar um debate e apontar algumas pistas para uma reflexão crítica sobre a práxis da educação para a/ou em cidadania. Para tanto, tomamos como lócus de investigação uma escola da rede pública estadual Rev. Caminhos da Educação: diálogos, culturas e diversidades, Teresina, v. 1, n. 3, p. 174-193, Mai./Ago. 2021 
do município de Teresina-PI, onde, por meio de conversas informais e sobretudo, da observação procuramos perceber se e como essa escola vem compreendendo e promovendo o reconhecimento da diversidade e a formação para a cidadania. Ainda enquanto instrumento de coleta de dados, nos utilizamos da entrevista semiestruturada, por entender que esse tipo de entrevista, nos ajudaria a melhor compreender as ações e práticas discursivas no interior da escola, acerca de tal prática.

O trabalho está organizado com essa introdução onde apresentamos a temática, bem como objetivos e a metodologia da pesquisa e mais duas seções. $\mathrm{Na}$ primeira, faremos um breve debate sobre a noção de cidadania e como essa noção chega à escola, enquanto um conteúdo a ser trabalhado e apontamos uma certa tensão entre a ideia de igualdade presentes nos debates sobre cidadania e as questões relacionadas ao reconhecimento das diferenças postas pelos movimentos sociais. Nesse sentido, nos questionamos, é possível uma educação para cidadania tendo como base os ideais de igualdade proposto pela Declaração Universal dos Direitos Humanos ao mesmo tempo em que defendemos o princípio do respeito à diversidade e a diferença? Na segunda parte, tentaremos demonstrar a partir de dados do trabalho de campo, como essa tensão se reverbera na escola e finalizamos com algumas considerações.

\section{Cidadania e educação}

O termo cidadania tem sido utilizado ao longo do tempo e com distintas concepções para caracterizar a qualidade de cidadão em um determinado momento histórico (OLIVEIRA, 2015) tendo sido idealizado como um conjunto de direitos e deveres dos sujeitos que pertencem a uma determinada comunidade (MARTINS \& MOGARRO, 2010).

Historicamente falando, a ideia de cidadania surgiu na Grécia e foi se instituindo, sobretudo a partir do estado moderno, os chamados Estados-Nação e 
tem como base a constituição de direitos civis, políticos e sociais1 (OLIVEIRA, 2015). Para José Murilo de Carvalho (2002; p. 09) a ideia de cidadania inclui várias dimensões podendo algumas destas dimensões estar presentes e outras não. Ainda segundo este autor, uma cidadania plena que combine liberdade, participação e igualdade para todos foi um ideal desenvolvido no ocidente e que talvez seja inatingível, entretanto tem servido como um parâmetro para julgar a qualidade da cidadania dos países em determinados momentos históricos. Seguindo essa acepção, para ser um cidadão pleno, o indivíduo deve ser titular dos três direitos (civis, políticos e sociais), seriam cidadãos incompletos aqueles indivíduos que possuíssem apenas alguns, e os que não tivessem nenhum dos direitos seriam considerados não cidadãos.

Aqui no Brasil, a cidadania desenvolveu-se de forma limitada por nossa própria condição social e histórica. Durante mais de três séculos fomos caracterizados pela “ausência do poder público, estado, nação e cidadania” (OLIVEIRA, 2015: 168). Tal período foi definido pelo historiador José Murilo de Carvalho (2002), como um período no qual o poder público era precário, que não havia garantia de igualdade, os direitos civis beneficiavam a poucos, assim como os direitos políticos e os direitos sociais sequer existiam. Dessa forma, como não havia república, isto é, não havia sociedade política; também não havia cidadãos.

Ora, se considerarmos que a condição para cidadania é a garantia de direitos (civis, políticos e sociais), essa noção parece estar ausente em quase toda a história do Brasil. Carvalho (1996) em seu artigo "Cidadania: tipos e percurso" demonstra que se no período colonial brasileiro houve uma completa ausência de cidadania, nos períodos que se seguiram essa noção foi sendo gradativamente construída, através de avanços e retrocessos, para finalmente culminar numa expansão do conceito com a Constituição Democrática de 1988. Esta, constituição inaugurou um novo momento

\footnotetext{
1 Direitos civis são aqueles ditos como fundamentais, direito à vida, à liberdade, à propriedade e à igualdade perante a lei. Os direitos políticos se referem à participação do cidadão no governo da sociedade sendo seu exercício limitado a uma parcela da população e consiste na capacidade de fazer demonstrações políticas, de organizar partidos, de votar, de ser votado; já os Direitos sociais garantem a participação na riqueza coletiva e incluem o direito à educação, ao trabalho, ao salário justo, à saúde, à aposentadoria.

Rev. Caminhos da Educação: diálogos, culturas e diversidades, Teresina, v. 1, n. 3, p. 174-193, Mai./Ago. 2021
} 
na história da cidadania brasileira, pois segundo Carvalho (2002) foi a partir desta que a cidadania "caiu literalmente na boca no povo", substituindo o próprio povo na retórica política; possibilitou ainda que todos os direitos pudessem ser exigidos pelos cidadãos.

A Constituição Federal de 1988 como apontada acima, inaugurou uma nova concepção para o termo cidadania, colocando-a como um dos fundamentos da República Federativo do Brasil. Desde então, a cidadania, pauta-se na legitimidade dos direitos, na obrigatoriedade de sua efetivação pelo estado e na possibilidade de participação dos cidadãos, cabendo à política educacional a tarefa de prepará-los para seu exercício.

Educar para a cidadania tem sido uma constante preocupação dos pedagogos e dos sistemas educativos através dos tempos (MARTINS \& MOGARRO,2010), no entanto, aqui no Brasil essa preocupação é bem recente e tem como ponto de partida a Constituição Federal de 1988, conforme dito acima. Esta, em seu artigo 205, afirma que a educação é um direito de todos e dever do Estado e da família, e que será desenvolvida visando ao pleno exercício de cidadania e sua qualificação para o trabalho. Seguindo nesta mesma direção, a Lei de Diretrizes e Bases da Educação Nacional, Lei no 9.394/96 destaca a educação como dever da Família e do Estado, e que inspirada nos princípios da liberdade e nos ideais de solidariedade humana tem por finalidade o pleno desenvolvimento do educando e seu preparo para o exercício pleno da cidadania. Além da LDB, outros documentos normativos, também evocam a educação e a escola como responsáveis pela "produção da cidadania", como por exemplo, os Parâmetros Curriculares Nacionais - PCN, s; Plano Nacional de Educação - PNE e Base Nacional Comum Curricular - BNCC.

Moaci Alves Carneiro (1998), ao refletir sobre os princípios e fins da educação, salienta que a concepção de cidadania proposto no artigo $2^{\circ}$ da LDB, centra-se na condição básica de ser cidadão - ser titular de direitos e deveres - a partir de duas condições - uma universal assegurada na Carta de Direitos Humanos da Organização das Nações Unidas (ONU) e uma particular, embasada em cláusula pétrea da Constituição Federal - "todos são iguais perante a lei”. 
Aqui é importante ressaltar que, o fato de termos garantido formalmente o direito à cidadania e que o Estado tenha feito um esforço sistemático na defesa e proteção dos direitos fundamentais, inclusive desenvolvendo um conjunto de leis e políticas públicas voltadas para a conquista e o exercício da cidadania, não significa que na realidade não haja uma violação sistemática destes direitos. Nesse sentido, concordamos com Candau (2013) quando afirma que, basta lermos os jornais ou assistirmos os informativos televisivos, para que sejamos expostos às múltiplas e diversificadas formas de violações de direitos, ao contínuo desrespeito às normativas de proteção e defesa da dignidade humana, bem como às múltiplas formas de violência, desigualdade social, corrupção e discriminações que constituem a realidade cotidiana. Tal situação, segundo a autora, demonstra que não basta a construção de um arcabouço jurídico em relação à garantia de direitos, é necessário sobretudo, que estes sejam internalizados no imaginário social, nas mentalidades individuais e coletivas.

É neste processo de internalização e disseminação do arcabouço jurídico no imaginário social e coletivo que reside a importância da educação e dos processos educativos, pois é por meio destes que a cidadania deve ser construída, haja vista a incumbência dada a política educacional de formar para a cidadania. Entretanto, convém nos questionar: como pensar a formação para cidadania e como a educação poderia ajudar a construí-la se a própria educação2 enquanto direito social é negado à grande parte da população? É possível educar para o pleno exercício da cidadania, quando direitos básicos são negados, enquanto vivenciamos situações de exclusão, preconceito, discriminação e o alargamento das desigualdades em nosso meio e presenciamos o não reconhecimento da diversidade no espaço educacional? Como a escola e a educação poderiam contribuir com esse processo formativo considerando todas essas questões apontadas acima?

Ressaltamos que não temos a intenção de responder tais questionamentos, no entanto eles servirão como um guia para nossa reflexão sobre educação para e em

2 Aqui estamos nos referindo a educação escolarizada, ou seja, aos sistemas de ensino formal.

Rev. Caminhos da Educação: diálogos, culturas e diversidades, Teresina, v. 1, n. 3, p. 174-193, Mai./Ago. 2021 
cidadania. Aqui no Brasil, de acordo com Carvalho (2002), temos percorrido um longo caminho para construir o cidadão brasileiro. Desde a "independência" até a atualidade esse caminho vem sendo percorrido, com avanços e retrocessos, no entanto, nos últimos 60 anos, essa luta tem sido cada vez mais constante. Desde o final dos anos de 1960, os movimentos sociais organizados vêm reivindicando e exigindo o reconhecimento dos seus direitos. A partir de então desencadeou-se um "novo movimento social" (Dietz, 2012) denominado multiculturalismo e no seio desse movimento os diversos grupos sociais, passaram a exigir reconhecimento de suas identidades/diferenças. Este movimento encontrou no campo educativo, um espaço privilegiado para o debate sobre as diferenças e reconhecimento dos direitos das minorias. Isso porque a escola, segundo Semprini (1999) é um espaço consagrados à formação do indivíduo, pois segundo ele,

(...) a educação tem igualmente a missão de conduzir a pessoa ao pleno amadurecimento de suas capacidades. Ao permitir-lhe forjar seu espirito crítico e escolher de modo autônomo entre várias possibilidades aquela que melhor lhe convém, a escola é a segunda instancia libertadora do indivíduo (SEMPRINE, 1999:46).

Ao reconhecer a educação e a escola como elementos centrais na construção da cidadania, o Estado delegou à política educacional a responsabilidade para a formação cidadã e tem desenvolvido leis e ações visando a garantia desse direito. No campo educacional, por exemplo, algumas ações foram desenvolvidas tendo como base a ideia de igualdade. Nestas o exercício da cidadania baseia-se no princípio da igualdade - todos são iguais - na tentativa de diminuir as desigualdades que afetam diversas esferas da sociedade.

No Brasil, há uma grande desigualdade no acesso ao ensino, segundo cor e raça. Isso não se deve à ideia que pretos e partos sejam biologicamente inferiores aos brancos - isso é um argumento equivocado e datado do século XIX. A diferença de acesso ao ensino no Brasil está atrelada ao fato de que, durante muitos anos, negras e negros não tiveram nenhum acesso regular no país. Por exemplo, 
o regulamento de instrução provincial de São Paulo, de 1869, proibia a matrícula de escravos e, 1887, outro regulamento reiterou essa proibição. [...] Na província do Rio de Janeiro, o regulamento de 1847, proibia não apenas as pessoas escravizadas de frequentar escolas, como também "pretos africanos, sejam libertos ou Livres" (LINS, 2016, p.97).

A educação enquanto direito humano é também um direito social, portanto necessária ao exercício pleno da cidadania devendo ser estendido a todos, contudo essa parece ainda não ser a realidade. Embora a ideia de cidadania seja reivindicada como um direito humano universal, que visa a garantia de direitos e a diminuição das desigualdades, ela por um lado, parece está restringida a uma parcela da população e por outro, parece que a ideia de universalidade se confunde com homogeneidade. Dessa forma é preciso entender que o ideal de cidadania, enquanto direito universal, não é sinônimo de homogeneidade, bem como não é o contrário de diversidade, mas de desigualdade.

É, portanto, nessa perspectiva que Candau (2012) nos chama a atenção para a necessidade de pensamos a educação, cidadania e direitos humanos, desde uma perspectiva crítica e alargada, pois pensar universalidade e igualdade, não significa pensar homogeneidade, e afirma:

Concebido na perspectiva da igualdade, o direito a educação é afirmado procurando-se garantir uma escola igual para todos. Nesta perspectiva, sistema de larga escala de avaliação são implementados, municípios e estados elaboram currículos para todas as suas escolas, e produzindo material didático, padronizado, cadernos de exercícios para todos os alunos, entre outros aspectos está sendo elaborado, no momento atual, um currículo comum em nível nacional. Nesta perspectiva, a igualdade é muitas vezes interpretada como homogeneização e uniformização do sistema (CANDAU 2012:721).

É seguindo nessa perspectiva apontada pela autora que pretendemos entender como a educação para a cidadania vem sendo praticada em uma escola da cidade de Teresina-PI. Buscando compreender o processo ideal de igualdade trabalhado no 
Educar para a diversidade e cidadania: compreensões, desafios e perspectivas

lócus educacional e a maneira como questões relativas às diversidades são pensadas para reconhecer e valorizar as diferenças ou simplesmente homogeneizá-las?

\section{Cidadania e diversidade na escola: discurso e prática}

O nosso lócus de investigação é uma escola da rede pública estadual, localizada na zona leste da cidade de Teresina-PI. Estabelecida em um bairro periférico, a escola foi fundada em 13 de março de 1994, último ano do Governo Freitas Neto (19911994). $\mathrm{Na}$ época de sua fundação, a escola fazia parte de um projeto que vinha sendo implementado em todo o Brasil denominado - Centro de Atenção Integral à Criança e ao Adolescente - CAIC3, que durante a década de 90, fora idealizado para atender comunidades carentes com alta densidade populacionais.

Localizada entre bairros, vilas e favelas, inicialmente (1994 a 2001), a escola atendia exclusivamente alunos do Ensino Fundamental. Em 2002 inicia-se um processo para a implementação do ensino médio regular, devido ao aumento crescente da população no entorno da escola, somada ao surgimento de outras escolas para o ensino fundamental. O currículo passa por uma alteração no ano de $2003 \mathrm{com}$ oferta do $9^{\circ}$ ano ao ensino médio e posteriormente ofertar o ensino médio integrado 4.

Atualmente a escola atende aproximadamente 600 alunos/as (divididos entre os turnos matutino, vespertino e integral). Em termos de estrutura física, a escola possui além da estrutura administrativa, 16 salas de aulas, laboratório de informática, sala de vídeo, biblioteca, refeitório, quadra de esportes e sala destinada as atividades

3 De acordo com Menezes (2001) os CAICS foram criados no ano de 1991 pelo governo de Fernando Collor de Melo como parte do Projeto Minha Gente e teve como inspiração os Centros Integrados de Educação Pública (CIEPs), do Rio de Janeiro e implantados na gestão do então governador Leonel Brizola. O objetivo dos CAICS, era prover a atenção à criança e ao adolescente, envolvendo a educação fundamental em tempo integral, programa de assistência à saúde, lazer e iniciação ao trabalho entre outros.

4 No ensino integrado, os discentes cursam além das disciplinas da base curricular correspondente ao ano/serie em que estão matriculados, disciplinas voltadas para um curso técnico escolhido com base na oferta da escola.

Rev. Caminhos da Educação: diálogos, culturas e diversidades, Teresina, v. 1, n. 3, p. 174-193, Mai./Ago. 2021 
voltadas para o PIBID e Residência Pedagógica (RP/CAPES) 5. Para atender a comunidade escolar, além do corpo diretivo, conta com 50 professores/as das mais diversas áreas do conhecimento.

Como dito acima, o corpo discente é de aproximadamente 600 alunos, pertencentes as mais diversas camadas sociais. Em sua maioria, são pretos e pardos, vivendo em situação de vulnerabilidade social. Segundo informações da própria gestão da Escola, a grande maioria dos alunos, pertencem a extratos sociais muito baixo e por esta razão, precisam muitas vezes fazer uma opção entre a escola e o trabalho. Aqueles que tentam conciliar as duas coisas - escola e trabalho - muitas vezes encontram dificuldades na própria escola, pois o cansaço advindo da carga de trabalho não permite que os mesmos tenham um bom aproveitamento em sala de aula e acabam desistindo.

Formar para o exercício da cidadania, tem sido a principal meta a ser atingida pela escola. Em seu Projeto Político Pedagógico (PPP) é destacado como principal objetivo, "ofertar serviços, objetivando a formação de cidadãos críticos, capazes de agir no exercício da cidadania, por meio da valorização do potencial de cada um e do respeito a todos sem distinção" (PPP: 2014:19).

Aqui percebemos que o objetivo perseguido pela escola em seu processo educativo, está relacionado a construção de uma visão crítica da sociedade, almejando formar cidadãos conscientes de seus direitos e deveres e acima de tudo, que respeitem a todos sem qualquer distinção e que possam encontrar formas de sobrevivência e convivência com dignidade e bem estar. Nesse sentido, a cidadania, parece estar relacionada diretamente a aquisição de direitos, a consciência crítica, ao bem está e a dignidade.

50 Programa de Bolsa de Iniciação à Docência (PIBID) e Residência Pedagógica (RP) fazem parte do pacto entre Governo Federal, Governo do Estado, Secretária de Educação, Institutos Federais, Faculdades, Universidades (federais e/ou estaduais) e Escolas Públicas que são fomentados pela Coordenação de Aperfeiçoamento de Pessoal em Nível Superior (CAPES), com o objetivo de proporcionar o início e continuidade de graduandos dos cursos de licenciaturas na docência.

Rev. Caminhos da Educação: diálogos, culturas e diversidades, Teresina, v. 1, n. 3, p. 174-193, Mai./Ago. 2021 
Considerar essa dimensão da formação para a cidadania é importante, pois nos leva a questionar como a diversidade social, cultural, religiosa, de gênero e sexo presente na escola está sendo percebida e trabalhada desde uma perspectiva prática, pois formar para a cidadania também inclui o respeito as diferenças. Nesse sentido, o PPP da escola, afirma que as singularidades que permeiam o espaço educacional, devem ser reconhecidas nos planos de ensino, no intuito de contribuir com a formação de indivíduos para que estes sejam capazes de conviver e respeitar o diferente, assim,

[...] no âmbito de uma política da igualdade, incorpora a igualdade formal. Seu ponto de partida é o reconhecimento dos direitos humanos e o exercício dos direitos e deveres da cidadania, como fundamento da preparação do educando para a vida civil. Se expressa na equidade pelo acesso à educação [...], e outros benefícios sociais e no combate de todas as formas de preconceito por motivo de raça, sexo, religião, cultura, condição econômica, aparência ou condição física [...] (PPP, 2014: p. 22).

O exposto acima, nos conduz a outra reflexão, a ideia de uma política da igualdade tendo como ponto de partida o reconhecimento dos direitos humanos, parece colocar em evidência uma tensão entre igualdade e diferença, pois a ideia de igualdade defendida na Declaração de Direitos Humanos, parece não se coadunar com uma política da diferença. Assim, se a ideia de formação para a cidadania na escola, tem como base o idearia da Declaração dos direitos humanos, estaríamos contrapondo a valorização da diversidade? Ou mesmo deixando a questão da diferença ser tratada sem um aprofundamento das diferentes identidades existentes dentro do espaço escolar? O paradoxo estabelecido por essa questão hoje norteia debates nas diversas áreas de conhecimento e nesse sentido, é preciso estar alerta para que o discurso da igualdade, não legitime um padrão que criminaliza as diferenças. 


\section{Diversidade e educação: concepções da gestão e corpo docente da escola}

Depois de analisar o Projeto Político Pedagógico buscamos compreender como a gestão da escola, vem compreendendo e trabalhando as questões relativas à diversidade institucionalmente. Ao ser indagada sobre o tema, a gestão apresentou o seguinte "diversidade são as diferenças, pra mim são as diferenças, diversidade são as variedades das diferenças que tem que ser respeitadas, pautadas" (gestão escolar, 2018). Essa fala permite algumas observações. A primeira está no campo do comportamento do entrevistado que após definir os termos do que seria perguntada estava constantemente preocupada com a gravação. Não sei ao certo se a preocupação estava voltada para sair uma "boa fala" sobre o tema, ou mesmo, se o que está sendo dito condiz com o que "nós" esperávamos ouvir. Outra observação apontada era sobre a preocupação com o uso "da fala". Após determinar o anonimato e fins explicitamente acadêmicos seguimos para aprofundar sobre o que podemos entender por diversidade.

Levando em consideração a percepção de diversidade apontada pela gestão e tomando como base o respeito às diferenças por esta defendida, indagamos como a escola tem trabalhado essa situação do respeito aos diferentes, ou seja, como as diferenças são percebidas e tratadas no contexto da escola? Frente a nosso questionamento, fomos solicitados esclarecer sobre qual "tipo de diversidade" estávamos falando, pois de acordo com a gestão existe uma vasta variação do termo. Ainda assim conseguimos sua própria definição:

Mas me diga qual o tipo de diversidade que você está falando, pois pra mim, eu como gestão, ... vejo a diversidade dentro da escola, procuro fazer com que todos respeitem, sejam as diferenças, porque o nome já está falando di-ver-si-da-de, respeito em todos os sentidos (Gestão escolar, Entrevista realizada em 2018)

E continuou,

Não sei nem como eu te falo (...), por exemplo, a diferença do estado físico, está aí o elevador, mas não estar terminado. Vamos falar de diversidade sexual, aqui sempre tem palestra e eu procuro tratar Rev. Caminhos da Educação: diálogos, culturas e diversidades, Teresina, v. 1, n. 3, p. 174-193, Mai./Ago. 2021 
todos iguais, não tem diferença, se eu vejo um casal menino e menina, se beijando, eu brigo! se vejo menina e menina, também brigo! se vejo menino e menino também brigo! Do mesmo jeito que trato um trato todos, se for como no espaço físico como te falei temos bem ali o elevador parado, se for diversidade de saúde, como no caso, nós temos meninos especiais, trato tudo do mesmo jeito (Gestão escolar, Entrevista realizada em 2018) grifos nossos.

Os extratos apontam importantes pistas de como o termo diversidade é entendido na escola e maneira como se dá sua relação com a compreensão de cidadania. Ao incitar a definição do termo diversidade, ressaltamos afirmação de Dietz (2012) que destaca haver certa dúvida ou receio em aplicar ideia de diversidade, principalmente, na área da educação, pois muitas vezes a ideia de diversidade está relacionada com fenômenos específicos da cultura em sociedade como a religião, gênero e raça etc. e se tratando de diversidade de gênero e sexo, isso parecer ser um tabu, na escola. Talvez por isso, a necessidade de delimitar ou especificar sobre que tipo de diversidade se falava para situar e reconhecer a qual grupo cultural estaria tratando.

Já no segundo extrato a atenção volta-se para homogeneidade das diferenças, o discurso que estrutura o debate é a defesa cujos discentes não sofrem desigualdades, pois estes são tratados "da mesma forma". Aqui podemos ver os efeitos de mecanismos homogeneizantes, deixando de lado políticas públicas de reconhecimento das diferenças como a 11.645/2008 que valoriza a cultura afrobrasileira e indígena para construção da identidade nacional. Lei esta que embasou um evento para pensar o espaço da cultura negra na sociedade atual, tal como sua importância e valorização para nosso próprio patrimônio cultural. O evento que aconteceu de forma muito positiva e receptiva pelos discentes e gestão escolar foi elogiado em todos seus aspectos, danças, teatros, quadros, figuras públicas (negras) foram ponto alto para reconhecer e valorizar essa cultura. Ainda assim, tivemos que lembrar que existe um tratamento "igualitário" e a atividade seguinte do calendário “descontruiu" todo o debate do respeito a diferença, para uma reprodução de estruturas eurocêntricas. 
Para a Coordenadora Pedagógica pensar a diversidade requer antes de tudo uma definição, pois falar da diversidade "depende do ponto de vista, porque existe a diversidade cultural, diversidade de gênero, social, então depende do ponto de vista de como você vai trabalhar a diversidade" e tomando como exemplo a questão social afirma,

[...] aqui temos nesse em torno vilas, favelas, mas também a gente percebe que no âmbito da escola aumentou muito essa questão social, já tem conjuntos habitacionais com outro perfil, então eu acho que essa diversidade social, principalmente na nossa comunidade aqui a gente também tem que trabalhar, porque hoje, no entorno que a gente mora ... a diversidade social está ali, ... não tem como, você está bem ali em um lugar onde tem um ... tipo: conjunto habitacional, que o padrão é elevado, mas no entorno dela tem uma vila, existe uma casa de pessoas de baixa renda e que acho que a gente também tem que trabalhar essa questão aí, dentro do âmbito escolar (ENTREVISTA, 2018).

O que percebemos do exposto acima é que a noção de diversidade empregada pela coordenação pedagógica parece operar como sinônimo de desigualdade social, Contudo, não podemos resumir a diversidade apenas a questão social e econômica, haja vista que a diversidade se manifesta de forma diversa e plural, devendo ser tratada da mesma forma. Partindo dessa percepção da coordenadora sobre a questão social, questionamos como o trabalho com essa temática ajudaria no processo de formação para a cidadania e qual seria o papel da escola nesse campo.

[...] Eu trabalho a cidadania dentro da escola porque acredito que o cidadão ainda não vê a pessoas com baixa renda. ... aquela falta de respeito, olha o pobre e o negro com preconceito. A cidadania quando você trabalha na escola, você respeita o nível dela ... não é porque eu sou um doutor que as pessoas vão me tratar com mais respeito que as pessoas que tem um nível escolar mais baixo, então eu acho assim, que a questão da cidadania é o respeito ao outro. (ENTREVISTA, 2018)

Assim, nós na escola a gente busca trabalhar ela dessa forma, denominando a diversidade como eu citei, a social, etnias e nós 
estamos com um projeto sobre a consciência negra que eles estão trabalhando. Os alunos ... estão buscando mais conhecimento sobre o que é uma diversidade, certo que ela está direcionada a etnia, que no caso eles vão trabalhar os negros, mas sabemos que dentro do nosso Brasil, que é um Brasil que existe todas as etnias, a gente incorpora alguma coisa assim tipo: eu tenho uma pele branca e não sou negro, mas sabemos que tem uma mistura de raça aqui no Brasil. É nesse ponto de vista que nós trabalhamos, para eliminar o racismo, mas a diversidade é quando você trabalha a questão cultural, a música, a dança, quando você fala diversidade você abrange muita coisa (ENTREVISTA, 2018).

Os extratos acima nos permite que a concepção de cidadania defendida e trabalhada na escola, parece se limitar a questão socioeconômica e posição social, o que de não está errado, porem a cidadania ou exercício desta, está para além de uma posição social incluindo um conjunto de outros direitos. Já no segundo extrato percebemos que a compreensão de diversidade cultural parece estar relacionada com uma que chamamos de folclorização, pois se remete apenas a datas comemorativas em alusão a figuras que constituíram ou encabeçaram determinados movimentos e hoje fazem parte do imaginário nacional. Contudo, é importante frisar que para além de feriados no calendário, as principais demandas dos movimentos sociais que compõem a diversidade cultural brasileira, buscam o reconhecimento de suas especificidades, ou seja, a condição de cidadania, que é garantia de direitos, sobretudo o direito de ser quem são. Por esta razão é de fundamental importância que a escola trabalhe essa temática justamente para evitar que essa diversidade seja inviabilizada por questões de preconceito de raça, cor, sexo, ou classe social.

Ainda é pertinente notar que as falas acima citadas, seja da gestão ou coordenação pedagógica, apontam para uma falta de domínio do tema tratado, indicando a necessidade de um processo de discursão ou formação sobre diversidade e cidadania. Essa ideia de formação, para um melhor entendimento dos conceitos a serem trabalhados na escola, também é defendida por professores. Para o professor de Sociologia há uma necessidade de aprofundamento sobre certas temáticas, principalmente em relação a diversidade, segundo ele, 
[...] hoje em dia, já estou com mais de dez anos dando aula, o que hoje em dia está acontecendo é uma negação dessa diversidade, no caso das ideias disseminadas, a internet e tudo, a questão do preconceito quer dizer o seguinte: a questão das minorias, há uma construção da ideia de minoria como coitadinhos, como vítima, tem todo esse discurso que está chegando na escola e os próprios alunos imaginam isso, a questão do negro, do homossexual, como, vamos dizer assim ... vitimado, está tendo esse discurso, que é um discurso contra a própria ideia da diversidade, esse discurso que está entrando na escola e em outros espaços também (professor de Sociologia, 2018).

A compreensão e aceitação da diversidade no espaço escolar é de suma importância na formação para a cidadania, pois respeitar e ser respeitado em suas diferenças são direitos que de certa forma conferem dignidade à pessoa. Assim, ensinar o respeito aos diferentes é de suma importância, uma vez que estes ensinamentos estarão refletidos na construção da própria formação cidadã dos alunos. Destacar que negros, mulheres e indígenas são vítimas de um processo de exclusão e homogeneização de suas diferenças, contudo, na atualidade os mesmos devem ser vistos de forma positiva, a partir de uma revisão de concepções sobre diversidade e reconhecimento das diferenças no sentido de perceber as diferenças como elementos constitutivos de nossa sociedade e que portanto, devem ser respeitas e valorizadas. Dessa forma, estaremos educando no e para o exercício da cidadania.

\section{Considerações finais}

A título de conclusão deste artigo, gostaríamos de retomar o objetivo proposto. Analisar como na escola os termos - diversidade e cidadania - vinham sendo compreendidos e ao mesmo tempo entender como os processos de reconhecimento da diversidade e educação para o exercício da cidadania, estavam sendo realizados. A análise demonstrou que esses são temas que precisam de uma maior reflexão e estudo no âmbito educacional. No que diz respeito à diversidade, há uma compreensão do termo, contudo parece haver uma certa tendência em relacionálo às questões de gênero, o que de certa forma, faz com que, esse seja, um tema tabu Rev. Caminhos da Educação: diálogos, culturas e diversidades, Teresina, v. 1, n. 3, p. 174-193, Mai./Ago. 2021 
no espaço educacional. Essa situação era muito visível, nas falas da gestão e coordenação pedagógico, pois sempre que nos referíamos à diversidade, era nos exigido explicitar que tipo de diversidade estávamos falando. Da mesma forma, há uma certa tendência em relacionar a diversidade com desigualdade. Em uma das falas, da coordenação pedagógica sobre diversidade, ficou explicito essa relação diversidade/desigualdade. E apesar de haver um discurso do respeito as diferenças, ou seja, a diversidade, há pratica é homogeneizante.

Em relação à cidadania entendemos ser um tema que também carece de maiores reflexões no âmbito educacional. Pois educar para a cidadania, não deve ser apenas um discurso posto nos projetos pedagógicos das escolas, mas uma prática cotidiana das mesmas. Uma instituição que não respeitas as particularidades dos seus alunos, não está permitido o exercício, nem formando para a cidadania. Dessa forma, entendemos ser urgente uma reflexão da própria escola sobre suas práticas, bem como suas concepções de diversidade e cidadania.

Diante do exposto, entendemos que o grande desafio da educação e do sistema escolar, é estar aberto para o acolhimento das diferenças e percebê-las como um fator de enriquecimento e não ameaça. Acontece que, fomos orientados por um ideal de "igualdade" que não inclui os diferentes, sendo aí que está nosso grande desafio. Compreender que o direito a igualdade, ao exercício da cidadania não se relaciona com homogeneidade, pois temos o direito a ser tratados com igualdade/equidade, mas conservando as nossas diferenças. Educar para a diversidade e cidadania, a nosso ver, é promover o respeito e o reconhecimento das diferenças sem no entanto, hierarquizá-las ou homogeneizá-las.

Conceber uma educação cidadã é trabalhar por uma educação que integra o diferente com suas particularidades, subjetividades e singularidade culturais, onde o exercício do direito a igualdade não interfere ou deslegitima a promoção de diferenças. A busca pelo exercício da cidadania por meio do reconhecimento da diversidade é também uma busca pelo direito em reconhecer-se cidadão. Assim, para que haja uma educação para a diversidade e o exercício da cidadania, faz necessário uma mudança 
no processo de formação docente, pois somente com professores formados em uma perspectiva da diversidade e cidadania poderemos construir uma educação cidadã.

\section{Referências}

BRANDÃO, Carlos Rodrigues. O que é educaşão. São Paulo: Editora Brasiliense, 2007. (Coleção primeiros passos; 20).

BRASIL (2008). Lei 11.645, de 10 de março de 2008. Altera a Lei no 9.394, de 20 de dezembro de 1996, Brasília DF, mar 2008.

CANDAU, Vera Maria Ferrão. Direito à educação: diversidade e educação em direitos humanos. Educ. Soc., Campinas, v. 33, n. 120, p. 715-726, jul.-set. 2012 Disponível em http:/ /www.cedes.unicamp.br acesso em: 22 de junho de 2020.

CARVAlHO, José Murilo de. Cidadania no Brasil. O longo Caminho. $3^{a}$ ed. Rio de Janeiro: Civilização Brasileira, 2002.

CARVALHO, José Murilo. Cidadania: tipos e percursos. Revistas de Estudos Históricos,

v. 9, n. 18 (1996). Disponível em http://bibliotecadigital.fgv.br/ojs/index.php/reh/article/view/2029, acesso 02 de julho 2020.

CARNEIRO, Moaci Alves. LDB fácil: leitura critico-compreensiva: artigo a artigo. Petrópolis, RJ: Vozes, 1998.

DIETZ, Gunther. Multiculturalismo, interculturalidad y diversidad en educación. Una aproximación antropológica. Fondo de Cultura Económica; Edição: 2012.

GUSMÃO, Neusa Maria Mendes de. Antropologia e Educação: origens de um diálogo. Caderno CEDES. v.18, n.43, Campinas, dez. 1997.

LINS, Beatriz Accionly. Diferentes, não desiguais: a questão de gênero na escola. Ed. 1. São Paulo: Editora Reviravolta, 2016.

MENEZES, Ebenezer Takuno de; SANTOS, Thais Helena dos. Verbete CIACs (Centros Integrados de Atendimento à Criança). Dicionário Interativo da Educaşão Brasileira - Educabrasil. São Paulo: Midiamix, 2001. Disponível em: <https://www.educabrasil.com.br/ciacscentros-integrados-de-atendimento-a-crianca/ >. Acesso em: 21 de jul. 2020

MOGARRO, Maria João e MARTINS, Maria José D. A educação para a cidadania no século XXI. Revista Iberoamericana de Educación. N. 53 (2010), pp. 185-202.

OLIVEIRA, Lilian Tatiane Candia de. Educação e cidadania no Brasil: exploração e recorrências. Rev. educ. PUC-Camp., Campinas, 20(2):167-175, maio/ago., 2015. Acesso em 20 de junho 2020.

SAVIANI, Dermeval. Educação: do senso comum à consciência filosófica. 19. ed. Campinas, SP: Autores Associados, [1980] 2013.

SEMPRINI, A. (1999). Multiculturalismo. Bauru: EDUSC. 
Educar para a diversidade e cidadania: compreensões, desafios e perspectivas

RECEBIDO: 01/04/2021

APROVADO:03/05/ 2021
RECEIVED: 01/04/2021

APPROVED: 03/05/ 2021
RECIBIDO: 01/04/ 2021

APROBADO: 03/05/ 2021

Rev. Caminhos da Educação: diálogos, culturas e diversidades, Teresina, v. 1, n. 3, p. 174-193, Mai./Ago. 2021 